\title{
Information Support of Methods and Means of Non-Destructive Thermal Control of Heat-Shielding Properties of Samples
}

\author{
A.A. Churikov ${ }^{1, *}$, Yu.Yu. Gromov ${ }^{1}$, I.N. Ishchuk ${ }^{2}$, S.A. Barkalov and O.N. Morozova ${ }^{1}$ \\ ${ }^{1}$ Tambov State Technical University, Institute of Automation and Information Technology, Tambov, Russia, \\ ${ }^{2}$ Zhukovsky-Gagarin Air Force Academy, Meteorology Department, Voronezh, Russia
}

Received 25 April 2016; Accepted 20 November 2016

\begin{abstract}
The article studies the mathematical apparatus, being the basis of information support of the methods of non-destructive thermal control of heat-shielding properties of samples from solid heterogeneous or monolithic materials using rectangular heated surface area. When developing the mathematical apparatus we used Laplace and Fourier transformations which let the developed method of integral characteristics greatly simplify the search for solutions of multi-dimensional problems of thermal conductivity and get explicit and accurate analytical expressions to determine thermal conditions.
\end{abstract}

Keywords: thermal properties, heat conduction problem, non-destructive thermal control, temporal integral characteristics, volume integral characteristics.

\section{Introduction}

Manufacturers previous to us formulated the following basic technical requirements to the developed devices and systems:

1. The method provides a comprehensive control of the main thermal-physical properties (TPP) of nonconductive materials: thermal conductivity $\lambda$, thermometric conductivity $a$, volumetric heat capacity $\mathrm{C} \rho$ - without the loss of sample integrity.

2. The monitoring process should not take more than 15 minutes.

3. The device should allow to determine $\lambda, a, \mathrm{C} \rho$ with the maximum error in $10 \div 12 \%$, in the range of values for $\lambda=0,08 \ldots 0,5 \mathrm{~W} /(\mathrm{m} \mathrm{K})$.

4. The test sample thickness is at least $5 \mathrm{~mm}$ for samples with $\lambda$ to $0.2 \mathrm{~W} /(\mathrm{m} \cdot \mathrm{K})$ and at least 15 $\mathrm{mm}$ for samples with $\lambda$ more than $0.2 \mathrm{~W} /(\mathrm{m} \cdot \mathrm{K})$.

5. The size of the base of device probe placed on the surface of test material is at most $(70 \times 140) \mathrm{mm}^{2}$.

6. The instrument is designed as a construction of two separate units: the main unit (the operator panel), directly controlling the experiment and associated with data processing system (computer); and stemterm probe, which switching cable allows to carry it from the main unit at $5 \ldots 10 \mathrm{~m}$.

The developed methods calculated characteristics are derived from the solutions of thermal conductivity boundary

*E-mail address: wuhaidongxiaozi@126.com

ISSN: 1791-2377 @ 2017 Eastern Macedonia and Thrace Institute of Technology. All rights reserved. value problems, which took place on the ideological basis of integral characteristics (IC) method [1 - 8]. The main idea of the application of IC method for creating the methods lies in the possibility of simple and analytically accurate solutions of inverse multidimensional problem of thermal conductivity. In this paper we will use two IC types.

1. Name the integral $\mathrm{S}(\mathrm{t})$ extended to a certain fixed $\mathrm{V}$ area of the test body

$S(t)=\int_{V} \rho(x) \vartheta(x, t) d x$

as volume integral characteristics (VIC) of function $\vartheta(x, t)$ $[1,2,4]$.

2. Name the integral $\vartheta^{*}(x, p)$ by means of time variable $\mathrm{t}$

$\vartheta^{*}(x, p)=\int_{0}^{\infty} \exp (-p t) \vartheta(x, t) d t,, \mathrm{p}>0$

as temporal integral characteristics (TIC) of function $\vartheta(x, t)$.

(2) the classical Laplace transformation, when the parameter is a complex variable.

In a further study, we will use the parameter $\mathrm{p}$ as real and positive. It is a right choice of well-defined real and positive value of this parameter which allows you conveniently and easily calculate TIC optimal values (2) on the results of the experiment, where the function $U(x, t)$ - either the body temperature or the rate of heat flow density $q(r, t)$, going through a heated area of the sample surface. 


\section{A. Churikov, Yu.Yu. Gromov, I.N. Ishchuk, S.A. Barkalov and O.N. Morozova/ \\ Journal of Engineering Science and Technology Review 10 (2) (2017) 65-74}

The procedure of solving the boundary value problems of thermal conductivity by using the IC methods is showed in $[1-3,6,7]$. It is appropriate to quote the words of Academician A.V. Lykov:. "... Using the operating methods, many problems of exceptional difficulty, may be quickly and effectively solved, what is valuable to engineers and physicists. It is necessary to use methods for effective solution of these problems with a purpose of practical application" [8].

The applied IC method has the advantage that makes it possible to simplify the mathematical part of the work in solving multidimensional problems of thermal conductivity and get clear and accurate analytical expressions for determining the TPP.

In our work, when developing the NDT of TDTP method, Laplace [4] and Fourier [4, 9, 13] integral transformations necessary for solving boundary problems of thermal conductivity were used. Let's introduce in further application some types of IC which will be used in the work and differs by weighting functions form. For surface temperature $U(r, 0, t)=U(x, t)$ and heat flow $q(r, t)$ - they are the following:

1) the time integral characteristic (TIC) of body temperature

$$
U^{*}(r, z, p)=\int_{0}^{\infty} \exp (-p t) U(r, z, t) d t
$$

and heat flow

$$
q^{*}(r, p)=\int_{0}^{\infty} \exp (-p t) q(r, t) d t
$$

2) surface-temporal integral characteristic (STIC) of body temperature

$$
\tilde{U}_{D}^{*}(\xi, 0, p)=\int_{0}^{\infty} \int_{0}^{\infty} \exp (-p t) \cos (x \xi) U(x, t) d t d x
$$

and heat flow

$$
\tilde{q}_{D}^{*}(\xi, p)=\int_{0}^{\infty} r q^{*}(r, p) \cos (x \xi) d t d x
$$

3) the volume integral characteristic (VIC) of body temperature

$$
\tilde{U}_{D}(\xi, z, t)=\int_{0}^{\infty} U(x, z, t) \cos (x \xi) d x
$$

4) the volume temporal integral characteristic (VTIC) of body temperature

$$
\tilde{U}_{D}^{*}(\xi, z, p)=\int_{0}^{\infty} U^{*}(x, z, p) \cos (x \xi) d x
$$

In $(5 \div 8)-\mathrm{D}$ indexes correspond to the Cartesian coordinates. Variables $\mathrm{p}$ and $\xi$ here and elsewhere are considered as valid and positive. If $\mathrm{p}$ and $\xi$ are arbitrary value, we see: (3), (4) - the Laplace integral transformation;
(5), (6), (8) - are consequently held Laplace and Fourier integral transformations.

Most often, NDT are subjected to the solid-state products and samples, but we are faced with the need to investigate TPP of these matters, but different structure: mushy, disperse, free-flowing materials and heterogeneous medium [14]. A number of researchers and founders of thermal physics believes that we define the effective values of the TPP for these materials with sufficient accuracy [14].

The most common methods and devices [15] for the NDT of TPP contain the linear or point temperature sensors. The structure of heterogeneous or bulk material eliminates such types of sensors application, as it will appear considerable error in temperature measurement with a possible penetration of point sensor in a microgap between the material particles.

Therefore, the main idea of this work is the creation of sensitive elements, used in NDT of TPP aids, and, namely, the surface integral devices which can measure not only point temperature, but some definite temperature integral of the heated area of sample surface. We have done work on creation of methods and devices NDT of TPP, based on the surface of integrating temperature converters (hereinafter temperature integrators - TI), allowed to get information about the surface area temperature in the form of stripes. The numerical measurement result will be obtained in the shape of

$$
S(t)=\int_{v} \beta(v) U(v) d v
$$

where $\mathrm{v}$ - the plotted range of temperature integration $\mathrm{U} ; \beta$ (v) - weight function determined the shape and form of TI.

Flat TI in a form of strip or rectangle $(2 \ell$ width and $2 \mathrm{~L}$ length) is applied for NDT of TPP samples and products having flat surface area, as well as products and samples of cylindrical shape having a sufficiently large radius of surface curvature (to be positioned the strip on the line surface parallel to the cylinder); samples and products made of material with the anisotropy along the coordinate axes.

2. Theoretical foundations of the method with the application of heated strip surface temperature integrator

Let's illustrate a detailed solution of the boundary value problem of thermal conductivity. The thermal process model is as follows:

Suppose that the following conditions are realized in the experiment:

1. The test body with reference to the thermal effect is semibounded:

$-\infty<x<\infty, \quad-\infty<y<\infty, \quad z \geq 0$ (Fig. 1 )

2. The heat flow with density $q(x, t)$ is applied to the surface $z=0$ of the body through endless strip

$-\ell \leq x \leq \ell, \quad-\infty<y<\infty$

3. On the rest of the surface $|x|>\ell,-\infty<y<\infty, z=0$ of semibounded body the heat exchange is missed; 
4. The test body is isotropic and its thermal properties are not dictated by temperature;

5. In the initial time $(t=0)$ the temperature is constant (take it equal to zero).

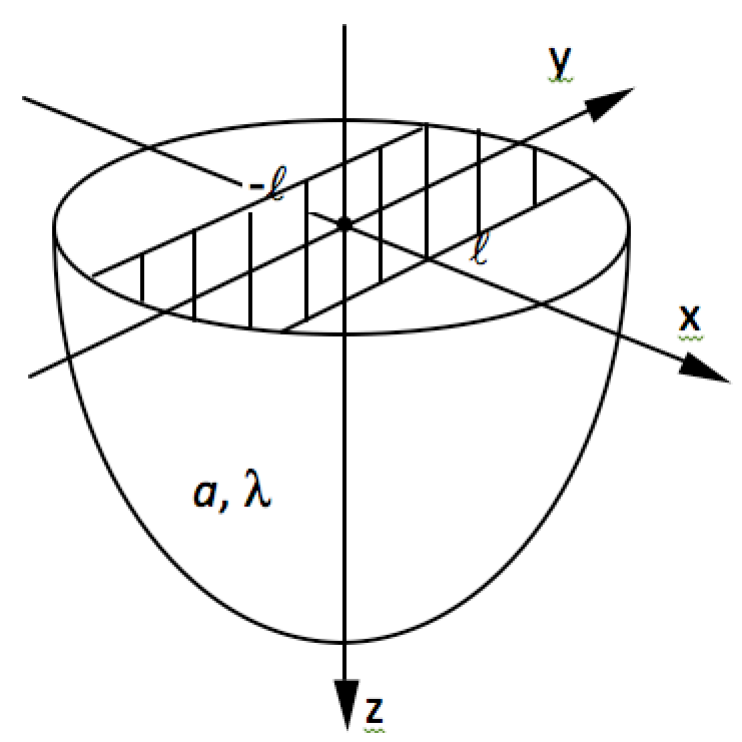

Fig. 1.Investigated sample model

Under this assumption for any point of time $t>0$ the excess temperature $U(x, y, z, t)$ of the test body does not depend on the coordinate $\mathrm{y}$. Then the temperature $U(x, y, z, t) \equiv U(x, z, t)$ is the solution of the following boundary value problem:

$$
\begin{aligned}
& \frac{\partial U(x, z, t)}{\partial t}=a\left(\frac{\partial^{2} U(x, z, t)}{\partial x^{2}}+\frac{\partial^{2} U(x, z, t)}{\partial z^{2}}\right), \\
& t>0,-\infty<x<\infty, \quad 0<z<\infty \\
& U(x, z, 0)=0, U(x, z, t) \rightarrow 0, x, z \rightarrow \infty ;
\end{aligned}
$$

$$
\left.\frac{\partial U(x, z, t)}{\partial z}\right|_{z=0,|x| \leq \ell}=-\frac{q(x, t)}{\lambda},\left.\quad \frac{\partial U(x, z, t)}{\partial z}\right|_{z=0,|x|>\ell}=0 .
$$

Apply to the problem (10) - (12) a spatial integral Fourier cosine transform [13]. The following formula will be correct for this task:

$$
\frac{p}{a} \bar{U}^{*}(s, z, p)=-\left.\frac{\partial U^{*}(x, z, p)}{\partial x}\right|_{x=0}-s^{2} \bar{U}^{*}(s, z, p)+\frac{\partial^{2} \bar{U}^{*}(s, z, p)}{\partial z^{2}}
$$

Where $\bar{U}^{*}(s, z, p)$ is the integral characteristic (IC) of temperature in the field of time transformations (Laplace) and in the field of (Fourier cosine transform) integral transformations.

A condition of TPP non-destructive testing requires information receiving in the experiment about temperature and heat flow only on the surface $z=0$ of the test body. Therefore, we will further consider STIC for $z=0$, i.e.

$$
\bar{U}^{*}(s, 0, p) \equiv \bar{U}^{*}(s, p)=\frac{\bar{q}^{*}(s, p)}{\lambda \sqrt{p / a+s^{2}}} .
$$

Let us suppose that we know the integral characteristics of temperature and heat flow for real parameter values $s$, and two different $\mathrm{p}_{1}$ and $\mathrm{p}_{2}$, i.e.

$$
\begin{aligned}
& \bar{U}^{*}\left(s, p_{1}\right)=\frac{\bar{q}^{*}\left(s, p_{1}\right)}{\lambda \sqrt{p_{1} / a+s^{2}}} \\
& \bar{U}^{*}\left(s, p_{2}\right)=\frac{\bar{q}^{*}\left(s, p_{2}\right)}{\lambda \sqrt{p_{2} / a+s^{2}}} .
\end{aligned}
$$

Then the unknown thermal coefficients of the formulas are in an explicit form:

$a=\frac{p_{2}\left[\bar{U}^{*}\left(s, p_{2}\right) \bar{q}^{*}\left(s, p_{1}\right)\right]^{2}-p_{1}\left[\bar{U}^{*}\left(s, p_{1}\right) \bar{q}^{*}\left(s, p_{2}\right)\right]^{2}}{s^{2}\left\{\left[\bar{U}^{*}\left(s, p_{1}\right) \bar{q}^{*}\left(s, p_{2}\right)\right]^{2}-\left[\bar{U}^{*}\left(s, p_{2}\right) \bar{q}^{*}\left(s, p_{1}\right)\right]^{2}\right\}}$,

$\lambda=\frac{1}{s} \sqrt{\frac{-p_{2}\left[\frac{\bar{q}^{*}\left(s, p_{1}\right)}{\bar{U}^{*}\left(s, p_{1}\right)}\right]^{2}+p_{1}\left[\frac{\bar{q}^{*}\left(s, p_{2}\right)}{\bar{U}^{*}\left(s, p_{2}\right)}\right]^{2}}{p_{1}-p_{2}}}$.

These formulas are very attractive, as provide obtaining the estimated dependence for determination of thermal characteristics in explicit form $[1,16]$. But for the technical implementation we need information of the temperature field in the subspace $z=0$ for the field $|x|>\ell$ to calculate STIC of body temperature $\bar{U}^{*}(s, p)$ and heat flow $\bar{q}^{*}(s, p)$ (5)-(6). But as $-\infty<x<\infty$, then it requires to create a special device measuring the temperature in different points of the surface $\left[x_{1}, \ldots x_{2}\right]$, or a special integrator with a large manipulation area in the field $|x|>\ell$. We have also made a series of experiments using a thermal imager. But there is a big problem of the measurement accuracy of radiative characteristic (emissivity coefficient) of bulk sample surface. As the formulas (15)-(16) use the numerical value of STIC temperature and heat flow then the application of thermal imager caused a significant measure of inaccuracy of surface temperature numerical value.

The need for NDT of TPP by the values of integral temperature came about from the study of disperse materials with heterogeneous structure, which explains the need to measure the temperature in a certain area or section. We created a device that uses in the strip heat a flat stripe integrator from the resistance thermometer detector (RTD). Let's establish the theoretical basis and calculated characteristics for TPP definition on this integrator base.

As long as the surface temperature for given boundary problem (10)-(12) is not the function of coordinate $\mathrm{y}$, the temperature of $U(x, y, t,) \equiv U(x, t)$.

Name $S_{n}(p)$ as the integral characteristic of strip temperature. To solve the problem (14) we use inverse Fourier cosine transformation and obtain STIC of the temperature which under the condition that the heat flow inside the strip $|x| \leq \ell$ is known and its density does not 
depend on the coordinate $\mathrm{x}$, i.e. $\left.q(x, t)\right|_{|x| \leq \ell}=q(t)$, will be as follows:

$U^{*}(x, p)=\frac{2}{\pi} \frac{q^{*}(p)}{\lambda} \int_{0}^{\infty} \frac{\sin (s \ell) \cos (s x)}{s \sqrt{p / a+s^{2}}} d s$.

Put in this correspondence a dimensionless parameter $g(p) \equiv g=p \ell^{2} / a$ and result the following formula of strip STIC temperature:

$S_{n}^{*}(p)=\frac{2 q^{*}(p) \ell}{\pi \lambda} \int_{0}^{\infty} \frac{\sin ^{2} \mu d \mu}{\mu^{2} \sqrt{g+\mu^{2}}}$

Bring into use a traditional for us $[1,2]$ approach: assign two values of a parameter $\mathrm{p}_{1}$ и $\mathrm{p}_{2}\left(\mathrm{p}_{1} \neq \mathrm{p}_{2}\right)$. In this case, it will be known the numerical values of STIC $S_{n}^{*}\left(p_{1}\right)$ и $S_{*}^{*}\left(p_{2}\right)$ obtained from the experimental $S_{n}(t)$ values. The thermometric conductivity coefficient $a$ and thermal conductivity $\lambda$ are determined from the following formulas:

$a=p \ell^{2} / g$

$\lambda=\frac{2}{\pi} \frac{q^{*}\left(p_{i}\right)}{S_{n}^{*}\left(p_{i}\right)} \int_{0}^{\infty} \frac{\sin ^{2} \mu d \mu}{\mu^{2} \sqrt{g+\mu^{2}}}$.

For (19) and (20) the parameter $\mathrm{g}$ is from formula:

$\frac{S_{n}^{*}\left(p_{1}\right)}{S_{n}^{*}\left(p_{2}\right)} \cdot \frac{q^{*}\left(p_{2}\right)}{q^{*}\left(p_{1}\right)}=\frac{V(g)}{V(k g)}, k=\frac{p_{1}}{p_{2}}$,

being

$V(g)=\frac{2}{\pi} \int_{0}^{\infty} \frac{\sin ^{2} \mu d \mu}{\mu^{2} \sqrt{g+\mu^{2}}}$,

$V(k g)=\frac{2}{\pi} \int_{0}^{\infty} \frac{\sin ^{2} \mu d \mu}{\mu^{2} \sqrt{k g+\mu^{2}}}$.

By experimentally measured data of integrated characteristic $S_{n}(t)$ and the heat flow q (t) the numerical value of function is presented here:

$\Phi(p, k)=\frac{S_{n}^{*}\left(p_{1}\right)}{S_{n}^{*}\left(p_{2}\right)} \cdot \frac{q^{*}\left(p_{2}\right)}{q^{*}\left(p_{1}\right)}$,

for given values $p=p_{1}$ and $k\left(p_{2}=k p\right)$. Then we find the value of $g$ parameter tacitly expressed in the equation:

$\Phi(g, k) \equiv F(g, k)=\frac{V(g)}{V(k g)}$,

then by $g$ value $a$ is defined from (18) and $\lambda$ is from (20), and volumetric heat capacity: $c \rho=\lambda / \mathrm{a}$.
Works [1-6] show the methods and devices of TPP NDT, wherein the main measured parameter for the calculation of IC temperature and TPP is the temperature of heated surface center, i.e. $U(0,0,0, t) \equiv U_{n}(t)$. is measured. In addition to determine the TPP values it is applied the same approach as shown in [2]. In calculated formulas it is used a function

$F_{1}(g, k)=\int_{0}^{\infty} \frac{\sin \mu d \mu}{\mu \sqrt{g+\mu^{2}}} / \int_{0}^{\infty} \frac{\sin \mu d \mu}{\mu \sqrt{k g+\mu^{2}}}$.

Numerical analysis and the experiment demonstrated that the comparison of formulas (22) and (23) determined that the sensitivity of method used SIC of strip temperature $S_{n}(t)$, is higher than that of the method used $\mathrm{U}_{\mathrm{u}}(\mathrm{t})$ temperature of the central point of this stripe [16]. The result of these formulas comparison for the region $g \in[0,3 \ldots 1,7]$, which is functional for this method $[2,10]$ is shown in the chart (Fig. 2).

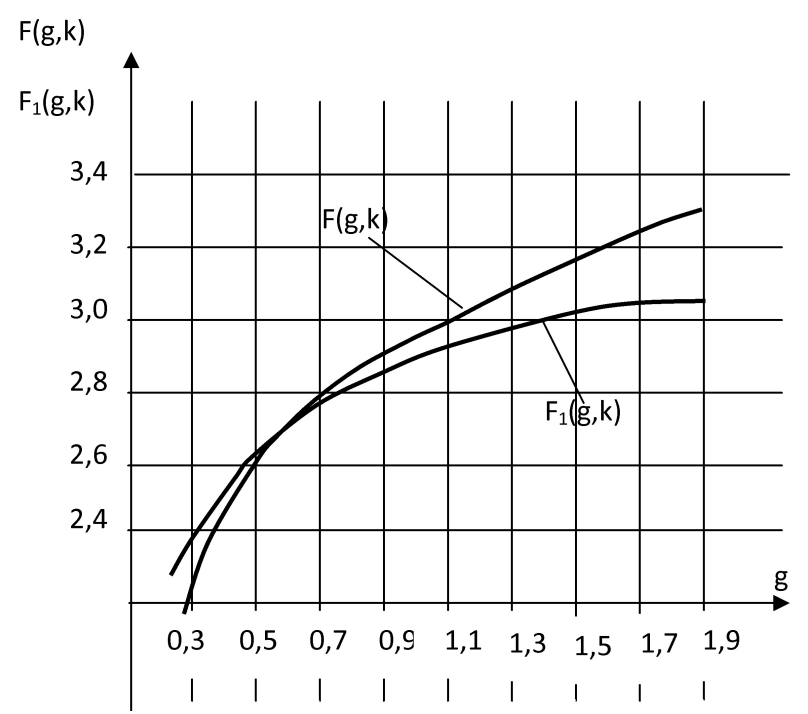

Fig. 2. Graphs of $F(g, k)$ function for the method of heated strip integrated characteristics and $F_{1}(g, k)$ function for the method of this strip center temperature

As we can see from the graphs (Fig. 2) virtually throughout the whole range of $g$ parameter application, it is carried out the following inequation:

$F_{g}^{\prime}(g, k)>F_{1 g}^{\prime}(g, k)$

indicating a greater sensitivity of $F(g, k)$ function to the $g$ parameter change, than $F_{1}(g, k)$ function. This leads to the conclusion about the greater sensitivity of NC TPP method, based on measuring the temperature of the whole heated surface area of the sample than the method based on measuring the temperature at one central point of the heated surface area.

3. Theoretical foundations of a method with the use of the temperature integrator of heated rectangular surface area 


\section{A. Churikov, Yu.Yu. Gromov, I.N. Ishchuk, S.A. Barkalov and O.N. Morozova \\ Journal of Engineering Science and Technology Review 10 (2) (2017) 65-74}

The model of thermal process is similar to the previous model, but the heat flow with the density of $q(x, t)$ is applied to the body surface of $z=0$ through the rectangle surface of $z=0,-\ell \leq x \leq \ell-L \leq y \leq L$ (Fig. 3).

The distribution of temperature $U(x, y, z, t)$ is described by solving the problem of heat conduction:

$$
\begin{aligned}
& \frac{\partial U(x, y, z, t)}{\partial t}= \\
& \mathrm{a}\left(\frac{\partial^{2} U(x, y, z, t)}{\partial x^{2}}+\frac{\partial^{2} U(x, y, z, t)}{\partial y^{2}}+\frac{\partial^{2} U(x, y, z, t)}{\partial z^{2}}\right) ;
\end{aligned}
$$

with $\mathrm{t}, \mathrm{x}, \mathrm{y}, \mathrm{z}>0$.

$U(x, y, z, 0)=0 ; U(x, y, z, t) \rightarrow 0$ with $\mathrm{x}, \mathrm{y}, \mathrm{z} \rightarrow \infty$.

$$
\begin{aligned}
& \left.\frac{\partial U(x, z, t)}{\partial z}\right|_{\substack{z=0 \\
x \leq \ell \\
y \leq L}}=-\frac{q(t)}{\lambda} ; \\
& \left.\frac{\partial U(x, y, z, t)}{\partial x}\right|_{x=0}=\left.\frac{\partial U(x, y, z, t)}{\partial y}\right|_{y=0}= \\
& =\left.\frac{\partial U(x, y, z, t)}{\partial z}\right|_{\substack{z=0 \\
x \leq \ell \\
y \leq L}}=0
\end{aligned}
$$

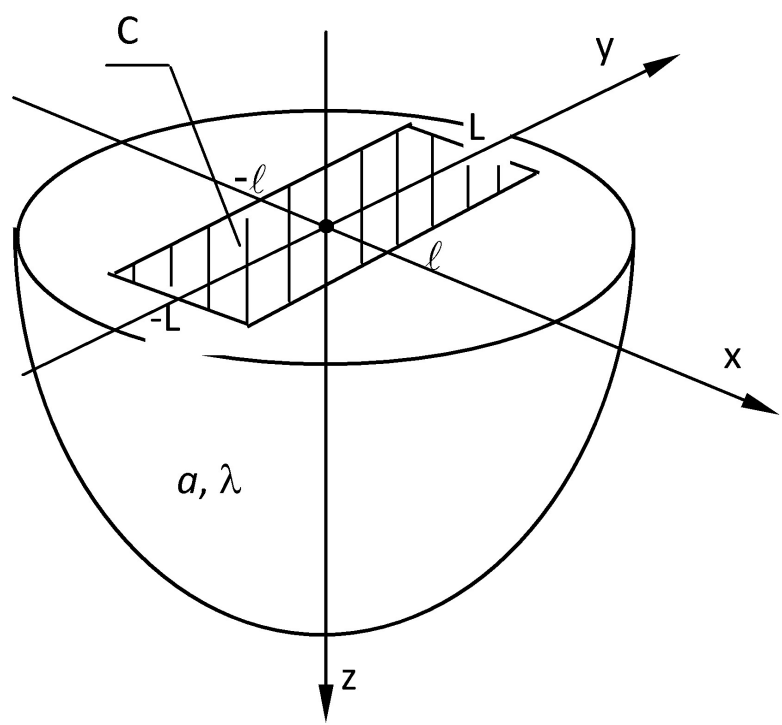

Fig. 3. The model of the sample heating by means of surface rectangle

Apply to this problem the consequent Laplace transformation, the integral cosine Fourier transformation for the $\mathrm{x}$ coordinate and cosine Fourier transformation for the $\mathrm{y}$ coordinate. Then, we show that known integrated temperature characteristics and the heat flow values for valid parameters $s, r$ and two different $p_{1}$ and $p_{2}$, that is

$$
\begin{aligned}
& \bar{U}^{*}\left(s, r, p_{1}\right)=\frac{\bar{q}^{*}\left(s, r, p_{1}\right)}{\lambda \sqrt{p_{1} / \mathrm{a}+s^{2}+r^{2}}}, \\
& \bar{U}^{*}\left(s, r, p_{2}\right)=\frac{\bar{q}^{*}\left(s, r, p_{2}\right)}{\lambda \sqrt{p_{2} / \mathrm{a}+s^{2}+r^{2}}} .
\end{aligned}
$$

The thermal diffusivity and thermal conductivity are determined explicitly by the formulas:

$\mathrm{a}=\frac{p_{2}\left(\bar{U}^{*}\left(s, r, p_{2}\right) \cdot \bar{q}^{*}\left(s, r, p_{1}\right)\right)^{2}-p_{1}\left(\bar{U}^{*}\left(s, r, p_{1}\right) \cdot \bar{q}^{*}\left(s, r, p_{2}\right)\right)^{2}}{s^{2}\left\{\left(\bar{U}^{*}\left(s, r, p_{1}\right) \cdot \bar{q}^{*}\left(s, r, p_{2}\right)\right)^{2}-\left(\bar{U}^{*}\left(s, r, p_{2}\right) \cdot \bar{q}^{*}\left(s, r, p_{1}\right)\right)^{2}\right\}}$

$$
\lambda=\frac{1}{s r} \sqrt{\frac{p_{2}\left(\vec{q}^{*}\left(s, r, p_{1}\right) / \vec{U}^{*}\left(s, r, p_{1}\right)\right)^{2}+p_{1}\left(\vec{q}^{*}\left(s, r, p_{2}\right) / \bar{U}^{*}\left(s, r, p_{2}\right)\right)^{2}}{p_{1}-p_{2}}}
$$

We assume that $\mathrm{q}$ does not depend on the coordinates $\mathrm{x}$ and y:

$\left.q(x, y, t)\right|_{|x| \leq \ell,|y| \leq L}=q(t)$.

We apply the Fourier cosine transformation with respect to $\mathrm{x}$ and $\mathrm{y}$ :

$q(s, r, p)=$

$=\int_{0}^{L}\left(\int_{0}^{\ell} q(p) \cos (s x) d x\right) \cos (r y) d y=\frac{q^{*}(p) \sin (s \ell) \sin (r L)}{s r}$.

STIC temperature for rectangular heater $S_{c}^{*}(p)$ :

$S_{c}^{*}(p)=\frac{1}{2 \ell} \cdot \frac{1}{2 L} \int_{-\ell-L}^{\ell} \int_{-L}^{L} U^{*}(x, y, z, p) d y d x$

We introduce the dimensionless parameters $g(p)=\frac{p \ell^{2}}{\mathrm{a}}, \mu=r L, v=s \ell, m=L / \ell$. We get:

$$
S_{c}^{*}(p)=\frac{q^{*}(p) \ell}{\lambda} \cdot \frac{4}{\pi^{2}} \int_{0}^{\infty} \frac{\sin ^{2} v}{v^{2}} \int_{0}^{\infty} \frac{\sin ^{2} \mu d \mu d v}{\mu^{2} \sqrt{\mu^{2} / m+g+\mu^{2}}} d r d s .
$$

Indicate

$$
V_{c}(g, m)=\frac{4}{\pi^{2}} \int_{0}^{\infty} \frac{\sin ^{2} v}{v^{2}} \int_{0}^{\infty} \frac{\sin ^{2} \mu d \mu d v}{\mu^{2} \sqrt{\mu^{2} / m+g+\mu^{2}}} d r d s .
$$

Then

$S_{c}^{*}(p)=\frac{q^{*}(p) \ell}{\lambda} \cdot V(g, m)$.

The aspect (30) is rather similar (18). Further, according to certain methods $[1,2,4] a$ and $\lambda$ can be determined.

\section{Theoretical foundations and design of the temperature integrator of bulk sample heated surface band}

In real devices the band will have the following finite sizes: $|x| \leq \ell,|y| \leq L$, so the temperature integral characteristics will be calculated using the following correspondence formula:

$S_{n}(t)=\frac{1}{4 \ell L} \int_{-\ell-L}^{\ell} \int_{L}^{L} U(x, y, t) d x d y$ 
In accordance with boundary value problem the temperature $\mathrm{U}(\mathrm{x}, \mathrm{y}, \mathrm{t}) \equiv \mathrm{U}(\mathrm{x}, \mathrm{t})$ does not depend on $\mathrm{y}$ coordinate, and this temperature distribution is symmetric about the center $\mathrm{x}=0$, therefore:

$$
S_{n}(t)=\frac{1}{\ell} \int_{0}^{\ell} U(x, t) d x
$$

Put in the $2 \mathrm{n}$ band thin (their heat capacity tends to zero) copper conductors (Fig. 4) that will be a single resistance temperature detector (RTD). The coefficient of copper temperature dependence is $\alpha=0,47 \cdot 10^{-3}[1 / c]$ [17]. As the band length temperature $U(x, y, t)=U(x, t)$ does not depend on the y coordinate, then the resistance of any string lying in the point $\mathrm{x}_{\mathrm{i}}$ :, where $2 \mathrm{~L}$ - the band length will be of (Fig. 4), $R_{0}=\rho 2 L(\mathrm{Ohm}), \rho$ - the length unit resistivity RTD $(\mathrm{ohm} / \mathrm{m})$. For each $\mathrm{i}$-th RTD string the resistance is equal to:

$$
R\left(U\left(x_{i}, t\right)\right)=R_{0}\left(x_{i}\right)\left(1+\alpha U\left(x_{i}, t\right) .\right.
$$

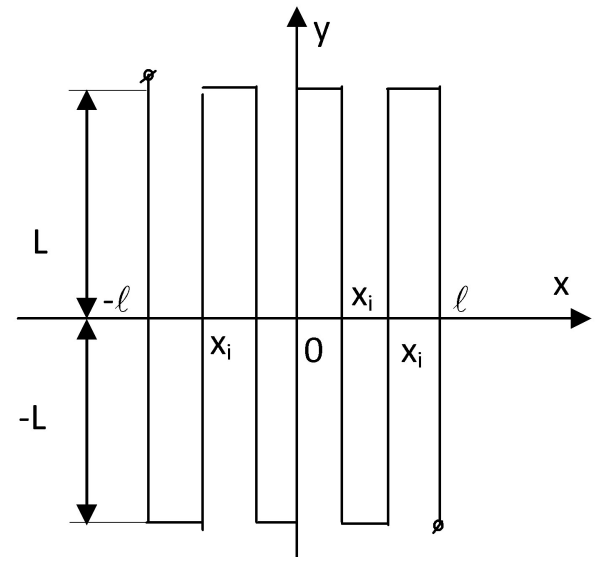

Fig. 4. Scheme of linear RTD connection into surface temperature integrator total

Consider the series resistance of $\mathrm{n}$ conductors, their $R_{o d}(t)=\left\{R\left(U\left(x_{1}, t\right)+R\left(U\left(x_{2}, t\right)+\ldots+R\left(U\left(x_{n}, t\right)\right\}, \quad\right.\right.\right.$ if $\quad \alpha_{1}=$ $\alpha_{2}=\alpha_{3}=\ldots \alpha_{\mathrm{n}}$, then

$$
R_{o d}(t)=\sum_{i=0}^{n} R_{0}\left(x_{i}\right)+\alpha \sum_{i=0}^{n} R_{0}\left(x_{i}\right) \cdot U\left(x_{i}, t\right)
$$

In our methods we accept that in solutions of the boundary value problems the temperature $U(x, t)$ is in excess related to the initial $U_{0}$, temperature, i.e. $U(x, t)=U_{u 3}(x, t)-U_{0}$. Then from (32), we find that the first term of the right side is the total resistance of the whole integrator at initial temperature:

$$
R_{o d}(0)=\sum_{i=0}^{n} R_{0}\left(x_{i}\right)=f(U(0))
$$

From (32) we get:

$$
\frac{R_{o d}(t)-R_{o d}(0)}{\alpha}=\sum_{i=0}^{n} R_{0}\left(x_{i}\right) U\left(x_{i}, t\right) .
$$

Take out from the right side the $\mathrm{R}$ factor the value of which is constant and can be set. Then, denoting

$K_{i}=\frac{R_{o}\left(x_{i}\right)}{R_{c}}$,

from the general rules of integration function one can write that:

$$
I(t)=\int_{x_{1}}^{x_{2}} U(x, t) d x=\left(\begin{array}{l}
\mathrm{a}_{1} U\left(x_{1}, t\right)+\mathrm{a}_{2} U\left(x_{2}, t\right) \\
+\ldots+\mathrm{a}_{n} U\left(x_{n}, t\right)
\end{array}\right) h, i \in[1, n] .
$$

where $h=\frac{x_{2}-x_{1}}{h}$ is the integration step; $A_{\mathrm{i}}$ - coefficients depending on the integration formula.

$$
\frac{R_{o d}(t)-R_{o d}(0) \cdot h}{\alpha R_{c}} \cong \int_{x_{1}}^{x_{2}} U(x, t) d x=I(t) .
$$

At that, it must be satisfied a condition, that $A=K_{i} \frac{R_{0}\left(x_{i}\right)}{R_{c}}$, and $\mathrm{h}$ is a distance between RTD (integrator) strips. Taking into account the symmetric property of the temperature field in the heating strip $-\ell \leq x \leq \ell$ and the fact that in real conditions we will place the integrator across the whole of heating strip, then:

$$
S_{n}(t)=\frac{1}{2 \ell} \int_{-\ell}^{\ell} U(x, t) d x \cong \frac{\left[R_{o d}(t)-R_{o d}(0)\right] h}{2 \ell \alpha R_{c}},
$$

where $h=\frac{2 \ell}{n} ; \mathrm{n}$ is a number of RTD (integrator) strips placing along the entire $2 \ell$ width of heating strip; $R_{c}=$ const. Integration of any function can be fulfilled by wellknown integration formulas in the theory of. Let's consider the possibility of these formulas using for placing the single RTD fiber in the area of temperature integrator. The required parameters here are the coordinates $\mathrm{x}=\mathrm{x}_{\mathrm{i}}$ of RTD strips location and their main characteristics: the electrical resistance $R_{0}(0)=R_{c}$ is an electrical resistance of a separate fiber at the $x_{i}$ point, entering into the series circuit of the whole temperature integrator.

Variant 1: Analyze the use of Newton-Cotes quadrature for equidistant $\mathrm{n}$ nodes (Fig. 5). The Weddle rule for $n=6$.

$$
\begin{aligned}
& I_{n}(t) \int_{-\ell}^{\ell} U(x, t) d x=\frac{41}{140} h\left(U\left(x_{0}, t\right)+5 U\left(x_{1}, t\right)+U\left(x_{2}, t\right)+6 U\left(x_{3}, t\right)+U\left(x_{4}, t\right)+\right. \\
& \left.+5 U\left(x_{5}, t\right)+U\left(x_{6}, t\right)\right)=\frac{41}{140} \frac{\ell}{3}\left[\left(U(-\ell, t)+5 U\left(-\frac{2}{3} \ell, t\right)+U\left(-\frac{2}{3}, t\right)+6 U(0, t)+\right.\right. \\
& \left.\left.+U\left(\frac{\ell}{3}, t\right)+5 U\left(\frac{2}{3} \ell, t\right)+U(\ell, t)\right)\right], \quad h=\frac{2 \ell}{6}=\frac{1}{3} \ell .
\end{aligned}
$$


It is obvious that $\mathrm{K}_{0}=\mathrm{K}_{2}=\mathrm{K}_{4}=\mathrm{K}_{6}=1, \mathrm{~K}_{1}=\mathrm{K}_{5}=5$, $\mathrm{K}_{3}=6$. Or $K_{0}=\frac{R_{0}\left(x_{0}\right)}{R_{\ell}}$. Hence $R_{\ell}=R_{0}\left(x_{0}\right)$. Then the first, third, fifth and seventh integrator fibers have the same resistance, i.e. have made of the same conductor, such as copper, of the same length, section and resistance. The second and sixth fibers have a resistance is fivefold, as $\mathrm{K}_{1}=5=5 \mathrm{R}_{0}\left(\mathrm{x}_{0}\right)$. In this case, the section of RTD conductor is 5 times less. It is possible to match, for example, a copper wire with cross-section of 5 times less. The third fiber is made of copper wire, which cross section is five times less than that of the first fiber. When carrying out in planar method, by coating the fibers on a substrate, then at equal coating thickness B the width of RTD fibers will be differed in 5 times (Figure 5.).

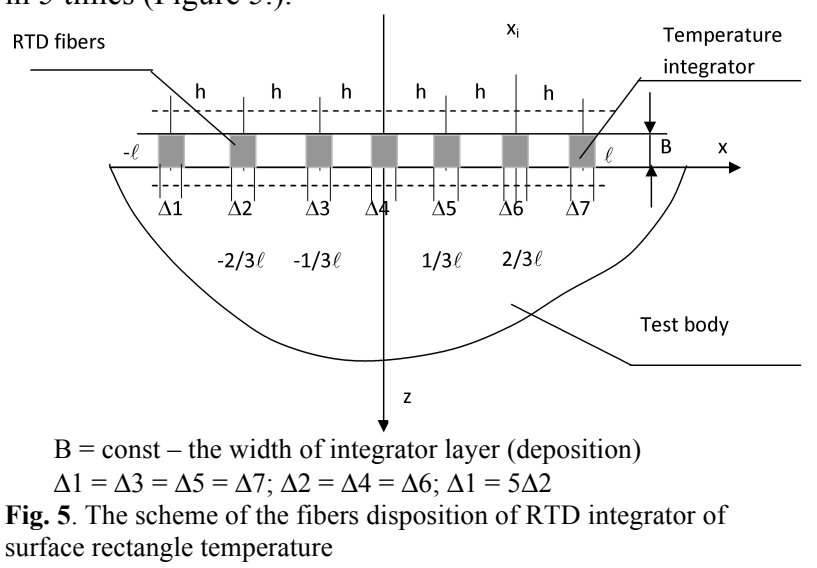

Then, the design equation for the integral temperature, measured by the given integrator, will be:

$S_{n}(t)=\frac{\left[R_{o d}(t)-R_{o d}(0)\right]}{\left[\alpha_{M} R_{c}\right]} \frac{41}{140}$,

where $\mathrm{R}_{0}(0)=\mathrm{R}_{\mathrm{c}}$ - the resistance of the first fiber of integrator placed on the line $\mathrm{x}=-\ell$.

This example is not quite successful for the implementation under real conditions, as it requires the application, in the integrator, of copper wire of quite different section or coating of different width RTD fibers in the integrator surface, which may affect the contact resistance and the measurement error.

Variant 2. We analyze the application of the rectangular formula for the calculation of integral for equidistant nodes integration $n$. (It is better if $\mathrm{n}$ is an even value).

$$
I_{n}(t) \cong \frac{2 \ell}{n}[U(0, t)+\ldots+U(n, t)] .
$$

In this case, whatever the value of $n$, we will put in the surfaces of directed strip the RTD fibers of equal parameters (length, section and material). It is very convenient and easily realizable (Fig. 6). Then the integral characteristic of the heated strip surface temperature is equal to:

$S_{n}(t) \cong \frac{\left[R_{o d}(t)-R_{o d}(0)\right]}{\alpha_{M} n R_{c}}$, where $\mathrm{n}$ is a number of RTD fibers conductors representing the temperature integrator of the heated strip surface (Fig. 6).

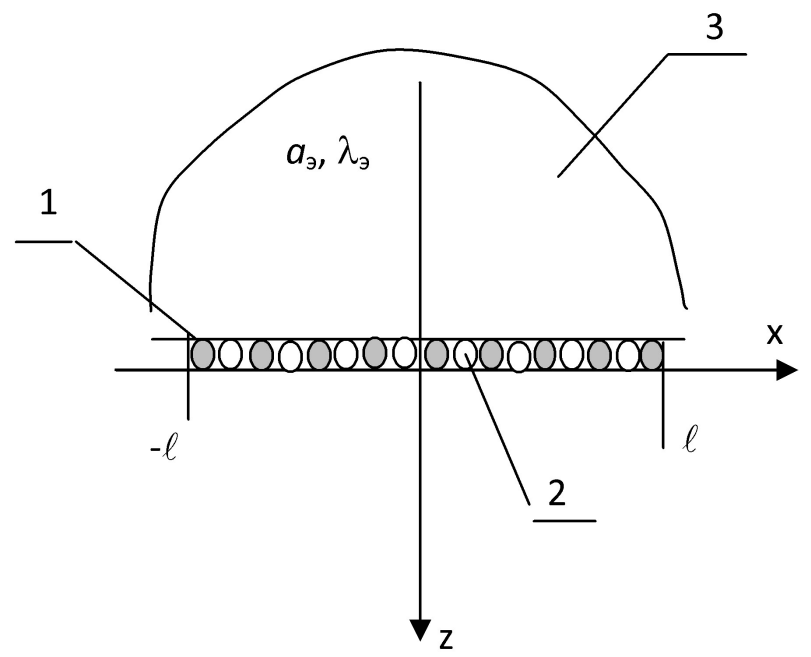

1 - electric heater fibers; 2 - RTD fibers, entering the surface TI;

3 - control sample probe substrate; 4 - test body.

Fig. 6. Scheme of heater and temperature integrator disposition on the substrate of measuring probe

In papers $[2,16,20]$ it has been shown that the optimal size of the width of the heated strip surface, is the value of $\ell$ $=(3 \ldots 3,5) \cdot 10^{-3} \mathrm{~m}$. Usually when creating the measuring device-probes a constantan wire of $0,07 \cdot 10^{-3} \mathrm{~m}$ in diameter is used for electric heaters. Since the stripe or rectangular integrator has a length of $2 \mathrm{~L}=88 \cdot 10^{-3} \mathrm{~m}$., the common calculation of the total resistance of TI strip shows that the total value of its initial resistance at $\mathrm{T}_{0}=293 \mathrm{~K}\left(20{ }^{\circ} \mathrm{C}\right)$ and for width of $2 \ell=6 \cdot 10^{-3} \mathrm{~m}$., will be equal to $\mathrm{R}_{\text {опт }}=2,1 \mathrm{ohm}$. At the same time on the width of $2 \ell=6 \cdot 10^{-3} \mathrm{~m}$ it will put 42 fibers of wire, alternating in succession: a heater fiber RTD fiber (Fig. 6).

The total length of the RTD, including in the integrator of surface temperature will be equal to $1.8 \mathrm{~m}$. When turning it to the bridging measuring scheme according to the principle shown in [2], its rather linear characteristic reaches a value of $250 \mathrm{mV} / \mathrm{ohm}$ in the absence of the influence on this value of the RTD internal heating from the bridge measuring current. This value is in $3 \ldots 4$ times higher than sensitivity of these common primary transducers (PT) as chromel-copel and chromel-alumel thermoelectric converters (RTD) [17]. Therefore, even in terms of a simple surface temperature measurement the value $\mathrm{SIC} \mathrm{S}_{\mathrm{II}}(\mathrm{t})$ is measured with an error less than the surface temperature of $\mathrm{U}(\mathrm{t})$, wherein mentioned TC are applied [18].

\section{Adequacy requirements of the heating process through the strip or rectangular surface area of a semi-bounded body}

It is necessary to estimate the adequacy requirements of the real heater having a finite length, the heater in the form of endless band, or, if it is impossible, to work appropriate corrections in the formulas.

Let's solve the corresponding direct problem of the thermal conductivity of a semi-bounded body heating with the initial temperature of zero, through a rectangular surface area with the size of $(2 \ell \times 2 \mathrm{~L})$ heat flow with the density of $\mathrm{q}(\mathrm{t})$, starting at time $\mathrm{t}=0$. 
The temperature distribution function $U(x, y, z, t)$ satisfies the differential equation

$$
\frac{\partial U}{\partial t}=\mathrm{a}\left(\frac{\partial^{2} U}{\partial x^{2}}+\frac{\partial^{2} U}{\partial y^{2}}+\frac{\partial^{2} U}{\partial z^{2}}\right), x, y, z>0, \quad t>0
$$

and the boundary conditions

IC $\mathrm{U}(\mathrm{x}, \mathrm{y}, \mathrm{z}, 0)=0$,

$\left.\operatorname{MC} \frac{\partial U(x, y, z, t)}{\partial x}\right|_{x=0}=0 ;\left.\quad \frac{\partial U(x, y, z, t)}{\partial y}\right|_{y=0}=0$.

$\left.\lambda \frac{\partial U(x, y, z, t)}{\partial y}\right|_{z=0}=$

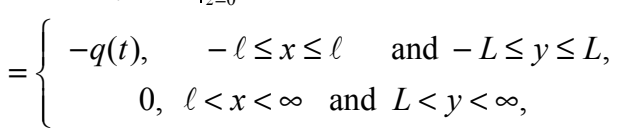

$U(x, y, z, t) \Rightarrow 0, \quad \mathrm{x}^{2}+\mathrm{y}^{2}+\mathrm{z}^{2} \rightarrow \infty$.

Solve the problem by the way of the consistent application of Laplace transformation by the time variable $t$ and Fourier cosine transformation in the $\mathrm{x}$ coordinate and the y coordinate. We obtain VTIC (8) temperatures of the test body:

$$
\tilde{U}_{c}^{*}(s, \eta, z, p)=\int_{0}^{\infty} \cos (s x) \int_{0}^{\infty} \cos (\eta y) \int_{0}^{\infty} e^{-p t} U(x, y, z, t) d t d x d y
$$

The equation (39) takes the form

$$
\left(s^{2}-\eta^{2}+\frac{p}{\mathrm{a}}\right) \tilde{U}_{c}^{*}=\frac{d^{2} \tilde{U}_{c}^{*}}{d z^{2}} .
$$

Writing down the general solution of this equation, subject to the corresponded transformed requirements we obtain

$$
\tilde{U}_{c}^{*}(s, \eta, z, p)=\frac{q^{*}(p) \sin (s \ell) \sin (\eta L)}{\lambda s \eta \sqrt{p / \mathrm{a}+s^{2}+\eta^{2}}} \exp \left(-z \sqrt{p / \mathrm{a}+s^{2}+\eta^{2}}\right) .
$$

By consequent application of the inverse Fourier cosine transformation on the $\mathrm{x}$ variable, and then on the $\mathrm{y}$ variable, we get an expression for the integral temperature characteristics at the point $\mathrm{x}=0, \mathrm{y}=0, \mathrm{z}=0$; i.e. in the center of heated rectangle:

$$
U^{*}(p)=\frac{2 q^{*}(p)}{\pi \lambda} \int_{0}^{\infty} \frac{\sin (\eta L)}{\eta} \cdot \frac{2}{\pi} \int_{0}^{\infty} \frac{\sin (s \ell)}{s \sqrt{p / \mathrm{a}+s^{2}+\mu^{2}}} d s d \eta .
$$

It turned out that for almost exact matching of the integral temperature characteristics in the cases of finite and infinite length $\mathrm{L}$ of the heaters in the range of $a=10^{-8} \ldots 10^{-6}$ $\mathrm{M}^{2} / \mathrm{c}, \mathrm{p}_{1}=0,016^{-1}, \mathrm{p}_{2}=0,128^{-1}, \ell=10^{-3} \ldots 10^{-2}$ it is sufficient that $\mathrm{L} \geq 5 \cdot 10^{-2}$.

In this case, their difference (relative) is no worse than $0.02 \%$.
If necessary to use the heaters smaller in length the following modified correlations $\mathrm{F}(\mathrm{g})$ and $\mathrm{V}(\mathrm{g})$ can be entered in calculating formula (17-23). If turning into a dimensionless parameter $g=\frac{p \ell^{2}}{\mathrm{a}}$, the rectangle side ratio $m=L / \ell$, and new variables $p_{1}=p, p_{2}=k p, v=s \ell$, then (21) and (23) will be in the form of:

$$
\begin{gathered}
F(\mathrm{~g})=\frac{\int_{0}^{\infty} \frac{\sin (\mu)}{\mu} \int_{0}^{\infty} \frac{\sin (v)}{v \sqrt{g+v^{2}+\mu^{2} / m^{2}}} d v d \mu}{\int_{0}^{\infty} \frac{\sin (\mu)}{\mu} \int_{0}^{\infty} \frac{\sin (v)}{v \sqrt{k g+v^{2}+\mu^{2} / m^{2}}} d v d \mu} ; \\
V(g)=\frac{4 \ell}{\pi^{2}} \int_{0}^{\infty} \frac{\sin (\mu)}{\mu} \int_{0}^{\infty} \frac{\sin (v)}{v \sqrt{g+v^{2}+\mu^{2} / m^{2}}} d v d \mu .
\end{gathered}
$$

To calculate the required time $T_{2}$, corresponding to the practical reaching of temperature field stationary distribution in the heated sample, it is necessary to find a specific numerical temperature correlation in the center point of the heater from heating time. If the heat flow density $q(x, t)=q$ $=$ const, the original for TIC temperature of heater center in the form of strip with width $2 \ell$.

$$
U^{*}(0,0, p)=\frac{2 q}{\pi \lambda p} \int_{0}^{\infty} \frac{\sin (s \ell)}{s \sqrt{p / \mathrm{a}+s^{2}}} d s
$$

It will be:

$$
U(0,0, t)=\frac{q \ell}{2 \lambda \sqrt{\pi}} \frac{\Phi(z)}{z} \frac{1}{t}, \text { here } z=\frac{\ell}{2 \sqrt{\mathrm{a} t}} .
$$

For rectangular heater with finite dimensions $(2 \ell \times 2 \mathrm{~L})$ the VIH temperature in the center is equal to

$$
U_{n}^{*}(0,0,0, p)=\frac{2 q}{\pi p \lambda} \int_{0}^{\infty} \frac{\sin \mu}{\mu} \frac{2}{\pi} \int_{0}^{\infty} \frac{\sin (s \ell)}{s \sqrt{p / \mathrm{a}+s^{2}+\mu^{2} / L^{2}}} d s d \mu
$$

In accordance with the theorem of argument change in the image in Laplace transformations may be written as [19], that

$$
\begin{aligned}
& L^{-1}\left(\frac{2 q}{\pi \lambda} \int_{0}^{\infty} \frac{\sin (s \ell)}{s \sqrt{p / \mathrm{a}+s^{2}+\mu^{2} / L^{2}}} d v\right)= \\
& =\frac{q \ell}{2 \lambda \sqrt{\pi}} \frac{\Phi(z)}{z} \frac{1}{t} \exp \left(\frac{-\mu^{2} \mathrm{a} t}{L^{2}}\right)
\end{aligned}
$$

Further, using the theorem of original integration [19], we get the following value from the image:

$$
\begin{aligned}
& L^{-1}\left(\frac{2 q}{p \pi \lambda} \int_{0}^{\infty} \frac{\sin (v \ell)}{v \sqrt{p / \mathrm{a}+v^{2}+\mu^{2} / L^{2}}} d v\right)= \\
& =\int_{0}^{\tau} \frac{q \ell}{2 \lambda \sqrt{\pi}} \frac{\Phi(z)}{z} \frac{1}{t} \exp \left(\frac{-\mu^{2} \mathrm{a} t}{L^{2}}\right) d t
\end{aligned}
$$


And, finally, using the theorem of integration by independent parameter [19], we get the formula for the temperature of the rectangle surface center:

$$
U_{n}(0,0,0, t)=\frac{2 q}{2 \pi \lambda \sqrt{\pi}} \int_{0}^{\infty} \frac{\sin \mu}{\mu} \int_{0}^{\tau} \frac{\Phi(z)}{z t} \exp \left(-\frac{\mu^{2} \mathrm{a} t}{L^{2}}\right) d t d \mu .
$$

To calculate this correlation we use approximate quadrature formulas [20] of the type:

$$
\int_{-1}^{1} f(t) d t=\sum_{i=1}^{N} A_{i} f\left(\xi_{i}\right)
$$

where $A_{i}, \xi_{i}$ are the coefficients and abscissa quadrature formulas given in [20]. The formula is exact when the subintegral function is described by a degree polynomial not higher than $(2 \mathrm{~N}-1)$.

Write down this expression in the form of:

$$
\begin{aligned}
& \frac{2 q \ell}{2 \pi \lambda \sqrt{\pi}} \int_{0}^{\infty} \sin (\mu) \phi(\mu) d \mu= \\
& =\frac{q \ell}{\lambda \pi \sqrt{\pi}}\left\{\int_{0}^{\frac{\pi}{2}} \sin (\mu) \phi(\mu) d \mu+\sum_{k=1}^{\infty}(-1) \mathrm{a}_{k}^{k-1}\right\}
\end{aligned}
$$

where

$$
\begin{aligned}
& \mathrm{a}_{k}=\int_{k \frac{\pi}{2}}^{k \pi} \sin (\mu)\left[\phi(\mu)-\phi\left(\mu+\frac{\pi}{2}\right)\right] d \mu ; \\
& \phi(\mu)=\frac{1}{\mu} \int_{0}^{\tau} \psi(t) \exp \left(-\frac{\mu^{2} t \mathrm{a}}{L^{2}}\right) d t ; \\
& \psi(t)=\frac{\Phi(z)}{z} \frac{1}{t}, \quad z=\frac{\ell}{2 \sqrt{\mathrm{a} t}} .
\end{aligned}
$$

The functions will be calculated numerically:

1. $\phi(\mu)=\frac{\tau}{\mu} \sum_{j=1}^{N_{2}} \psi\left(t_{j}\right) A_{j} \exp \left(-\mu^{2} \frac{\mathrm{a} t_{j}}{L^{2}}\right)$, where $t_{j}=\left(\xi_{j}+1\right) \frac{\pi}{2}$.

2. $\int_{0}^{\pi} \sin (\mu) \phi(\mu) d \mu=\frac{\pi}{2} \sum_{j=1}^{N_{2}} B_{j} \phi\left(\frac{\pi}{4} \xi_{j}+\frac{\pi}{4}\right)$,

3. $\mathrm{a}_{k}=\frac{\pi}{2} \sum_{j=1}^{N_{2}} B_{j}\left[\phi\left(k \pi+\frac{\pi}{4} \xi_{j}-\frac{\pi}{4}\right)-\phi\left(k \pi+\frac{\pi}{4} \xi_{j}+\frac{\pi}{4}\right)\right]$,

where $\quad B_{j}=A_{j} \sin \left(\frac{\pi}{4} \xi_{j}-\frac{\pi}{4}\right)$.

Note that the series using herein is Leibniz-type [21], (alternating series, the absolute value of its elements decreases with the increase of $\mathrm{j}$ number), then the final solution can be written as:

$U_{n}(0,0,0, t)=\frac{2}{\pi} \frac{q \ell}{2 \lambda \sqrt{\pi}}\left\{\begin{array}{l}\frac{\pi}{2} \sum_{j=1}^{N_{2}} B_{j} \phi\left(\frac{\pi}{4} \xi_{j}+\frac{\pi}{4}\right)+\sum_{R=1}^{N_{3}}(-1)^{R-1} \frac{\pi}{2} \sum_{j=1}^{N_{2}} B_{j} \phi\left(R \pi+\frac{\pi}{4} \xi_{j}-\frac{\pi}{4}\right)- \\ -\phi\left(R \pi+\frac{\pi}{4} \xi_{j}+\frac{\pi}{4}\right)\end{array}\right\}$,

where

$$
\begin{aligned}
& B_{j}=A_{j} \sin \left(\frac{\pi}{4} \xi_{j}-\frac{\pi}{4}\right) \\
& \phi(\mu)=\frac{\tau}{\mu} \sum_{i=1}^{N_{1}} \psi\left(t_{i}\right) A_{i} \exp \left(-\mu^{2} \frac{\mathrm{a} t_{i}}{L^{2}}\right), t_{i}=\left(\xi_{i}+1\right) \frac{\pi}{2} .
\end{aligned}
$$

To confirm the hypotheses of the output at the steady state of the temperature of rectangular heater center the calculations correlation were performed:

$$
\begin{aligned}
& U_{n}(0,0,0,(\tau+\Delta \tau)) \cong U_{n}(0,0,0, \tau)+ \\
& +\frac{2}{\pi} \frac{q \ell}{2 \lambda \sqrt{\pi}} \int_{0}^{\infty} \frac{\sin \mu}{\mu} \int_{\tau}^{\tau+\Delta \tau} \frac{\Phi(z)}{z} \frac{1}{t} \exp \left(-\mu^{2} \frac{\mathrm{a} t}{L^{2}}\right) d t d \mu
\end{aligned}
$$

Numerical calculations made on a computer by the formula (47), proved that the temperature of the center of heated rectangular surface area $\mathrm{z}=0$ with side ratio $\frac{\ell}{L} \geq \frac{1}{2}$ in the range of polymeric materials TPP: $\lambda=(0,08 \div 1,5)$ $\mathrm{W} /(\mathrm{m} \cdot \mathrm{K})$ и $a=(0,8 \div 4) 10^{-7} \mathrm{~m}^{2} / \mathrm{s}$, reached the steady state in less than 15 minutes by correspondence with $\mathrm{T}(\mathrm{t}+\Delta \mathrm{t}) \cong \mathrm{T}(\mathrm{t})$ with an error of no more than $\delta_{\text {стац }} \leq 0,01 \%$.

\section{Conclusions}

Thus, we can conclude:

- the sensor with a narrow rectangular heater, whose ratio is $\frac{\ell}{L} \geq \frac{1}{20}$ can be used for suggested method;

- transfer time to the second stage of the TPP study should be at least 15 minutes;

- for these conditions NDT of TPP conducting may be realized rather correctly by simple and correct calculated correlations $(14,15,18,19)$, obtained for the heater in the form of infinite band of $2 \ell$ width.

The elaborated mathematical apparatus for solving the thermal conductivity boundary problems is the base of information support of the thermal control of heat-shielding properties of samples from solid heterogeneous or monolithic materials using rectangular heated surface area.

\section{Acknowledgment}

The reported study was partially supported by RFBR, research project No. 15-08-02611 A.

This is an Open Access article distributed under the terms of the Creative Commons Attribution Licence

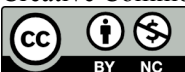




\section{References}

1. Vlasov V.V., Shatalov Ju.S., Zotov E.N., Labovskaja A. S., Mishhenko S.V., Pan'kov A.K., Ponomarev S.V., Puchkov N.P., Seregina V.G., Churikov A.A., Teplofizicheskie izmerenija. Spravochnoe posobie. (Thermophysical measurements. Guide book) - Tambov: Izdatel'stvo Vsesojuznogo nauchno issledovatel'skogo instituta rezinotehnicheskogo mashinostroenija, 1975. - $256 \mathrm{~s}$.

2. Churikov A.A. Metody i sredstva nerazrushajushhego kontrolja teplofi-zicheskih svojstv izdelij i obrazcov iz neodnorodnyh tverdyh materialov (Methods and means of non-destructive testing of thermal-physical properties of samples from hard materials): dis. ... d.t.n.: 05.11.13. / A.A. Churikov. - Tambov, 2000. - 650 s.

3. Shashkov A.G., Vojtenko A.G. Metod opredelenija teplofizicheskih ha-rakteristik na osnove preobrazovanija Laplasa (The method of thermal-physical characteristics determination on the base of Laplace transformation) // Inzhenerno-fizicheskij zhurnal, 1987. T. 52. - №2. - S. 287-293.

4. Shatalov Ju.S. Funkcional'no-integral'nye uravnenija teplofizicheskih harakteristiks. (Functional-integrated equations of thermal-physical characteristics) - M.: Nauka, izdatel'skaja firma «Fiz.-mat. lit». - 1996. - $256 \mathrm{~s}$.

5. Alekseev V.V., Gromov Yu.Yu., Samharadze T.G., Gubskov Ju.A., Ishhuk I.N. Matematicheskie modeli teplofizicheskih polej ob'ektov, zamaskirovannyh pod poverhnost'ju grunta. Chast' 1 . Teoreticheskie aspekty issledovanija teplofizicheskih polej ob'ektov, zamaskirovannyh pod poverhnost'ju grunta. Matematicheskie modeli optiko-teplofizicheskih polej ob'ektov, zamaskirovannyh pod poverhnost'ju grunta (Mathematical models of thermophysical fields of objects masked as ground surface. Part 1. Theoretical aspects of studying the thermophysical fields of objects masked as ground surface. Mathematical models of optical thermophysical fields of objects masked as ground surface) // Prikladnaja fizika i matematika (Applied physics and mathematics). - 2015. - №6. - S. 19-45.

6. Gromov Yu.Yu., Ishhuk I.N., Gubskov Ju.A., Baljukov A.M., Moiseev A.S. Reshenie kojefficientnoj obratnoj zadachi teploprovodnosti dlja vyjavlenija skrytyh ob'ektov s primeneniem BLA (Solving the coefficient inverse problem of thermal conductivity for undetected objects identification with the use of UAV) // Pribory i sistemy. Upravlenie, kontrol', diagnostika (Devices and systems. Control, monitoring, diagnostics). - 2014. №10. - S. 56-62

7. Gromov Yu.Yu., Baljukov A.M., Ishhuk I.N., Vorsin I.V. Matematicheskaja model' avtomatizirovannoj sistemy ispytanij IKzametnosti ob'ektov v uslovijah neopredelennosti (Mathematical model of automatic testing system of object infrared visibility in conditions of uncertainties) // Promyshlennye ASU i kontrollery (Industrial ACS and controllers). - 2014. - №7 - S.12-19.
8. Gromov Yu.Yu., Gubskov Ju.A., Ishhuk I.N., Parfir'ev A.V. Distancionnaja diagnostika izotropnyh materialov kompleksami BLA (Distance diagnostics of isotropic materials by UAV complex) // Promyshlennye ASU i kontrollery (Industrial ACS and controllers) . 2014. - №8. - S.46-50.

9. Alifanov O.M. Obratnye zadachi teploobmena. (Inverse problems of heat exchange) - M: Mashinostroenie, 1988.-280s.

10. Churikov A.A., Antonova L.L. Metodika opredelenija geometricheskih i vremennyh parametrov nerazrushajushhego kontrolja kompleksa teplofizicheskih svojstv (Determination methods of geometrical and temporal parameters of non-destructive testing for thermal-physical properties complex) // Kontrol'. Diagnostika. - M.: Mashinostroe-nie, 2006. - № 11. - S. 36 - 45.

11. Kartashov Je.M. Analiticheskie metody v teorii teploprovodnosti tverdyh tel. (Analytical methods in the theory of solid bodies thermal conductivity) / Je.M. Kartashov. - 3-e izd. M.: Vysshaja shkola, 2001. - $550 \mathrm{~s}$.

12. Lykov A.V. Teorija teploprovodnosti. (The theory of thermal conductivity) - M.: Vyssh. shk., 1967. - 599 s.

13. Korn G., Korn T. Spravochnik po matematike dlja nauchnyh rabotnikov $\mathrm{i}$ inzhenerov. (Mathematical guide for scientists and engineers) - M.: Nauka, 1968. - $720 \mathrm{~s}$.

14. Lykov A.V. Teplomassoobmen. Spravochnik. (Heat and mass exchange. Guide) - M.: Jenergija, 1978. $-480 \mathrm{~s}$.

15. Teplofizicheskie izmerenija i pribory. (Thermal-physical measurements and instruments) / E.S. Platunov, S.E. Buravoj, V.V. Kurepin, G.S. Petrov; Pod obshh. red. E.S. Platunova. - L.: Mashinostroe-nie, Leningr. otd-nie, 1986. - $256 \mathrm{~s}$.

16. Vlasov V.V., Shatalov Ju.S., Zotov E.N., Churikov A.A., Filin N.A. Metody i ustrojstva nerazrushajushhego kontrolja teplofizicheskih svojstv materialov massivnyh tel. (Methods and history of nondestructive testing of thermal-physical properties of massive body materials) - Izmeritel'naja tehnika, 1980, № 6, S. 42-45.

17. Tablicy fizicheskih velichin. (Tables of physical quantity) / Pod red. akademika I. K. Kikoina. - M.: Atomizdat, 1976. - 1008 s.

18. Churikov A.A. Integrirujushhie poverhnostnye preobrazovateli dlja kontaktnogo nerazrushajushhego teplofizicheskogo kontrolja (Integrated surface transformer for contact non-destructive testing) // Vestnik TGTU - 1988, T.4, № 2-3. - S. 283 - 291.

19. Ditkin V.A., Prudnikov A.P. Integral'nye preobrazovanija i operacionnoe ischislenie. (Integrated transformations and operating calculus) - M.: Nauka, 1974. - 544 s.

20. Krylov V.I., Shul'gina L.T. Spravochnaja kniga po chislennomu integrirovaniju. (Reference book in numerical integration) - M.: Nauka, 1966. - 372 s.

21. Gradshtejn, I. S. Tablicy integralov, summ, rjadov i proizvedenij [Tekst] (Tables of integrals, numbers, ranges and intersections) / I. S. Gradshtejn, I. M. Ryzhik // 7 -izd. - M.: Izd-vo BHV, 2011. $1100 \mathrm{~s}$. 